\title{
BMJ Open Multifactorial correlates of blood pressure in South Asian children in Canada: a cross-sectional study
}

\author{
Adeleke Fowokan, ${ }^{\circ 1}$ Zubin Punthakee, ${ }^{\circ} 2$ Charlotte Waddell, ${ }^{3}$ Miriam Rosin, \\ Katherine M Morrison, ${ }^{\oplus 2}$ Milan Gupta, ${ }^{2}$ Sumathy Rangarajan, ${ }^{4}$ Koon Teo, ${ }^{4}$ \\ Scott Lear ${ }^{3}$
}

To cite: Fowokan A, Punthakee Z, Waddell C, et al. Multifactorial correlates of blood pressure in South Asian children in Canada: a crosssectional study. BMJ Open 2019;9:e027844. doi:10.1136 bmjopen-2018-027844

- Prepublication history for this paper is available online. To view these files, please visit the journal online (http://dx.doi. org/10.1136/bmjopen-2018027844).

Received 13 November 2018 Revised 20 February 2019 Accepted 28 February 2019

Check for updates

(C) Author(s) (or their employer(s)) 2019. Re-use permitted under CC BY-NC. No commercial re-use. See rights and permissions. Published by BMJ.

${ }^{1}$ Department of Biomedical Physiology and Kinesiology, Simon Fraser University, Burnaby, British Columbia, Canada

${ }^{2}$ Department of Medicine, McMaster University, Hamilton, Ontario, Canada

${ }^{3}$ Faculty of Health Sciences, Simon Fraser University, Vancouver, British Columbia, Canada

${ }^{4}$ Population Health Research Institute, McMaster University, Hamilton, Ontario, Canada

Correspondence to

Adeleke Fowokan;

afowokan@sfu.ca

\section{ABSTRACT}

Objective We sought to explore various correlates of blood pressure (BP) and hypertension, and to identify the most important aggregate combination of correlates for BP in South Asian children.

Design Cross-sectional study

Setting Community-based recruitment in two Canadian cities

Participants South Asian children $(n=762)$ provided a range of physiological, lifestyle and social variables. BP was assessed using an automated device. Body mass index (BMI), waist circumference (WC), waist-to-height ratio (WHtR) and BP were transformed to z-scores using published standards.

Outcome measures Linear and logistic regression analyses were used to explore associations between the range of variables with $\mathrm{BP} \mathrm{z}$-scores and hypertension while stepwise regression was used to identify aggregate factors that provided explanatory capacity for systolic BP (SBP) and diastolic BP (DBP) z-scores.

Results $A$ range of variables were associated with $B P$ z-score and hypertension in unadjusted analysis. On adjustment for confounders, the association between age $(\beta=-0.054,95 \% \mathrm{Cl}=-0.078$ to 0.029$)$, female sex $(\beta=-0.208,95 \% \mathrm{Cl}=-0.350$ to -0.067$)$, height $(\beta=0.022$, $95 \% \mathrm{Cl}=0.011$ to 0.033 ), weight $(\beta=0.047,95 \% \mathrm{Cl}=0.040$ to 0.055$), \mathrm{BMl} z$-score $(\beta=0.292,95 \% \mathrm{Cl}=0.249$ to 0.336$)$, WC z-score $(\beta=0.273,95 \% \mathrm{Cl}=0.219$ to 0.326$)$, WHtR $z$-score $(\beta=0.289,95 \% \mathrm{Cl}=0.236$ to 0.342$)$, heart rate ( $\beta=0.016,95 \% \mathrm{Cl}=0.010$ to 0.022 ), child's perception of body image ( $\beta=0.183,95 \% \mathrm{Cl}=0.128$ to 0.239 ) and grip strength $(\beta=0.025,95 \% \mathrm{Cl}=0.007$ to 0.043 ) with SBP z-score remained. In stepwise regression, age, sex, BMI $z$-score, heart rate and weight accounted for $30 \%$ of the variance of SBP z-score, while age, BMI z-score, heart rate and daily fast food intake accounted for $23 \%$ of the DBP z-score variance.

Conclusion Our findings suggest that variables, such as age, sex, height, adiposity and heart rate, provide stronger explanatory capacity to BP variance and hypertension risk than other variables in South Asian children.

\section{INTRODUCTION}

South Asians comprise approximately 25\% of the world's global population ${ }^{1}$ and represent a significant portion of the visible ethnic

\section{Strengths and limitations of this study}

- Strengths of this study include its large sample size of South Asian children and,

- Its examination of a wide range of physiological, lifestyle and social risk factors in relation to blood pressure z-scores and hypertension in South Asian children.

- Limitation of this study includes its cross-sectional design, which limits the attribution of causality.

minority groups in countries such as Canada, the UK and the USA. ${ }^{2-4}$ Individuals of South Asian origin are known to be at increased risk of cardiovascular disease (CVD) relative to other ethnic groups in Western countries. ${ }^{56}$ These differences in CVD risk have also been shown to be present in South Asian children, suggesting that the risk differential in CVD risk factors and events experienced by this ethnic group starts from an early age. ${ }^{7}$

One of the major physiological risk factors for CVDs is high blood pressure (BP) or hypertension. ${ }^{8}$ Hypertension is also associated with an increased risk for stroke and kidney disease. ${ }^{8}$ Moreover, multiple studies have shown that high $\mathrm{BP}$ in childhood typically continues into adulthood ${ }^{9}$-including in South Asian populations. ${ }^{10}$ These findings suggest that it is important to prevent hypertension in childhood in order to address the potential cardiovascular and metabolic sequelae later in life.

In South Asian children, studies have demonstrated an increased prevalence of hypertension or higher BP levels relative to other ethnic groups. ${ }^{11} 12$ While there is evidence suggesting a disproportionately higher BP burden for South Asians, the exact factors implicated are relatively unclear. Given the fact that causes of high BP are known to be multifactorial, ${ }^{8}$ it is important to understand the various risk factors that might 
be responsible for the increased risk of high BP in South Asian children in general. Using a range of multifactorial variables (ie, variables across a range of different factors) that were identified in a recently published systematic review of children to be correlated with BP and hypertension in other children population groups; ${ }^{13}$ this study, therefore, aims: (1) to explore the associations between physiological (factors relating to biology), lifestyle (factors relating to behaviour) and social factors (factors relating to conditions in which people live, attend school, grow and develop) and BP in South Asian children and (2) to identify the most important aggregate correlates of BP in South Asian children.

\section{METHODS}

\section{Study design}

Participants included in this study were recruited as part of the Research in International Cardiovascular HealthLifestyles, Environments and Genetic Attributes in Children and Youth (RICH-LEGACY) study. This cross-sectional study was designed to investigate risk factors for CVD across South Asian children in Canada. Parents of participants provided written informed consent, while participants assented to take part in the study.

\section{Recruitment}

Elementary-school and high-school children $(\mathrm{n}=762)$ were recruited using community-based methods in two Canadian cities (Brampton, Ontario and Surrey, British Columbia) by convenience sampling between 2012 and 2016. Letters were first sent to school boards to identify elementary schools with a high rate of South Asian enrolment. Once schools were identified, packages containing an invitation letter, RICH-LEGACY study description and consent forms were sent to parents/guardians of children enrolled in the identified schools. Information stands were also placed at the participating elementary schools before and after school hours to reach out to parents with more information about the study. Additionally, the study was advertised through venues used by South Asian groups including newspapers, local television stations, community centres, worship centres and festivals. Inclusion criteria included: children (in elementary or high school) having at least three grandparents of South Asian origin and participants being able to provide consent (parents) and assent (children). Research assistants fluent in Hindi and Punjabi were responsible for participant recruitment and data collection. All the research assistants who were involved in the measurements undertook training together through simulator sessions and were retrained if variations in measurement protocol were observed by the research coordinator. This process was repeated for a few days to ensure accuracy and consistency among the research assistants in the assessment of the measurements collected in this study. In addition, written materials (including consent forms) were provided in English, Punjabi, Hindi and Urdu as needed.

\section{Participant assessment}

Participants for the RICH-LEGACY study were assessed regarding sociodemographic variables including age, sex and parental education. In certain cases, parents or guardians helped to complete certain sections of the child's questionnaire. Children's perception of body image was assessed using Stunkard's silhouettes, a rating scale from one to nine with increases related to increased silhouette size,$^{14}$ which assesses perception of size and body dissatisfaction. This figure rating scale has been shown to be a valid indicator of determining weight status in children. ${ }^{15}$ Feeding practices were assessed using the childhood feeding questionnaire. ${ }^{16}$ Exposure to bullying was assessed by asking participants if they had experienced bullying or violence at school. This variable was assessed because of its role as a known stressor in children and its possible impact on pathways known to be involved in BP regulation, such as the hypothalamicpituitary-adrenal axis. ${ }^{17}$ Additionally, level of acculturation was assessed using the Acculturation Rating Scale for Mexican Americans-II adapted for use in South Asians by Stigler et al. ${ }^{18}$ This scale assesses an individual's identification with their heritage based on different domains including language preferences, media preferences and preferences regarding food and other consumer goods using 24 questions. ${ }^{18}$ The adapted questionnaire is grouped into two scales: the Western scale and the traditional scale. The traditional acculturation score measures children's acceptance of traditional Indian cultural attributes while the Westernised acculturation score measures the degree to which South Asian children identify with the Western culture.

Participants completed a semiquantitative food frequency questionnaire $(\mathrm{FFQ})$ that assessed intake of fruits and vegetables, and fast foods consumption. The FFQ was adapted from the INTERHEART FFQ, which was validated in an international cohort that included South Asians. ${ }^{19}$ Physical activity was assessed using a standardised questionnaire that quantified sports and other activities including leisure, household chores and sedentary factors (screen time and homework) during school and outside of school over the past month. All activities were then expressed as metabolic-equivalent-of-task minutes. Self-reported exposure to secondhand smoke was assessed to characterise children's passive exposure to smoking and defined as a minimum of five consecutive minutes during which inhalation of other people's smoke occurs. Hand-grip strength, a measure of muscular strength, was measured on the non-dominant hand by study personnel with a Jamar dynamometer utilising standardised protocol. ${ }^{20}$

\section{Anthropometric characteristics}

Height was measured to the nearest $0.1 \mathrm{~cm}$ using a right angle triangle and a calibrated wall-mounted scale. Weight was measured to the nearest $0.1 \mathrm{~kg}$ with the subject in light clothing using an electronic scale. Body mass index (BMI) was first calculated from weight in kilograms divided by height in metres squared before being converted to z-scores using WHO growth references for young people aged $5-19$ years $^{21}$. 
Waist circumference (WC) was recorded in centimetres as the average of two measures taken halfway between the lower rib margin and the iliac crest against the skin following a normal expiration. WC was assessed using non-stretching measuring tape by trained team members. Waist-to-height ratio ( $\mathrm{WHtR})$ was then calculated by dividing WC by height. Both WC and WHtR were transformed to z-scores using published lambda-mu-sigma values for age and sex based on the third US National Health and Nutrition Examination Survey. ${ }^{22}$ Transforming the anthropometric measures to z-scores allowed for the standardised comparisons across populations of children of similar ages and sex.

\section{BP and Heart rate}

$\mathrm{BP}$ and heart rate were measured in the left arm using the Omron HEM-711DLX automated BP monitor with appropriate sized cuffs following $10 \mathrm{~min}$ of seated rest. Three $\mathrm{BP}$ and heart rate measures were taken over a 10-min period and the average of the three was recorded. Subsequently, BP was transformed to SD scores and percentiles adjusted for age, sex and height according to the fourth National High Blood Pressure Education Program (NHBPEP) working group in children and adolescents. ${ }^{23}$ Systolic and diastolic hypertension were defined using the NHBPEP recommendations as average systolic BP (SBP) or diastolic BP (DBP) equal to or greater than the 95th percentile for sex, age and height.

\section{Parental variables}

Parents of the children recruited for this study provided information on parental education (father's and mother's education). In a smaller subset of the South Asian children ( $n=271$ ), parental history of hypertension (yes or no) was assessed in order to explore the potential impact of heritable factors on children's BP z-scores and hypertension. Father's education was used as a proxy variable for socioeconomic status in this study. Fathers' education levels were categorised as: those with no formal education; those with primary/secondary school education; those with a trade school degree/diploma and those with a college or university degree. Parent's smoking status was self-reported and categorised as non-smoker, former smoker or current smoker.

\section{Statistical analysis}

All continuous variables were examined using P-P plots and found to be normally distributed. For descriptive analysis, continuous variables were presented as means and SDs while categorical variables were reported as counts and percentages. Independent t-test analysis was used to assess sex differences in continuous variables, while $\chi^{2}$ tests were used to assess sex differences in categorical variables.

To explore the associations among the range of physiological, lifestyle and social variables with SBP and DBP, unadjusted linear regression was used. These models were then adjusted for potential confounding effect of child age, sex and father's education. These confounders were selected based on their well-documented independent associations with the outcome variable in research studies. ${ }^{11} 13$ Although the conversion of BP to z-scores provides age-adjusted and sex-adjusted data, we chose to still include age and sex as confounders to adjust for potential residual effects unaccounted for by the reference charts used in this study. Similarly, unadjusted and adjusted (age, sex and father's education) logistic regression analysis was used to explore clinically relevant associations among the multifactorial variables with systolic and diastolic hypertension. While age and sex were identified as potential confounders in the association between the other variables assessed in this study with BP and hypertension, we also wanted to examine their independent associations with $\mathrm{BP}$ and hypertension. To do this, they were each removed from the list of confounders we adjusted for when exploring their effect on BP z-scores and hypertension (ie, sex was adjusted for age and father's education, while age was adjusted for sex and father's education).

To address the second study objective, stepwise multiple linear regression analyses were used to identify the combination of risk factors that best explained the variance in BP in South Asian children. The stepwise regression method enables the identification of the aggregate combination of correlates that has the highest contributory effect on the outcome variable. Specifically, for this analysis, we utilised the backward method to select the list of multifactorial correlates that provide a significant contribution to the outcome (SBP and DBP z-scores) using an entry criterion of $\mathrm{p}<0.05$ and a removal criterion of $p>0.10$. The specific list of correlates (age, sex, height, weight, heart rate, BMI z-score, WC z-score, WHtR z-score, parental history of hypertension, parental education, exposure to bullying and violence, traditional and western acculturation scores, physical activity in school and outside school, dietary variables and secondhand smoking) considered for introduction in the backward stepwise regression model were chosen a priori based on the literature evidence ${ }^{13}$ and whether they had a $p$ value $<0.05$ in unadjusted analysis. Using the aforementioned criteria, the following variables were considered in stepwise regression analysis: age, sex, height, weight, BMI z-score, WC z-score, WHtR z-score, heart rate, western acculturation score, child's perception of body image and grip strength. In addition to these variables, father's education, daily intake of fast foods and total daily intake were considered in DBP z-score models. The adjusted $\mathrm{R}^{2}$ value for each model provides the combined contribution of the variables in the model to the variance in BP z-scores. The full list of variables initially identified from the literature search was also considered in logistic regression models with hypertension. Statistical analysis was done using SPSS V.24.0. P values $<0.05$ were considered statistically significant. This study was written in line with the Strengthening the Reporting of Observational Studies in Epidemiology guidelines. ${ }^{24}$ 


\section{Patient and public involvement}

The research questions and outcome measures, in this study, were chosen by the team of researchers and clinicians with extensive experience working with the South Asian population to better understand the potential health risks faced by South Asian children. No patients were involved in the development of the research questions or study design. There are currently no plans to disseminate the results of this research study to study participants or to the relevant patient population.

\section{RESULTS}

This study included 360 boys (47\%) and 402 girls (53\%) ranging from 5.8 to 17.0 years (mean age $9.5 \pm 3.0$ years), with no statistically significant difference observed for age by sex (table 1). The prevalence of systolic hypertension in this population was $12 \%$. South Asian boys were more physically active outside school than girls $(p=0.04)$; higher WC z-score $(p<0.001)$; higher WHtR $\mathrm{z}$-score $(\mathrm{p}=0.02)$; lower heart rate $(\mathrm{p}=0.047)$; higher SBP z-scores $(p=0.001)$; higher prevalence of systolic hypertension $(p=0.01)$; lower traditional acculturation score $(p=0.02)$ and significantly higher exposure to bullying and violence at school $(\mathrm{p}=0.025)$.

\section{Correlates of SBP and systolic hypertension}

In unadjusted linear regression analysis with SBP z-scores, weight $(\mathrm{kg})(\beta=0.005,95 \% \mathrm{CI}=0.001$ to $0.01, \mathrm{p}=0.022)$, BMI z-score $(\beta=0.289,95 \% \mathrm{CI}=0.246$ to $0.333, \mathrm{p}<0.001)$, WC z-score $(\beta=0.266,95 \% \mathrm{CI}=0.213$ to $0.319, \mathrm{p}<0.001)$, WHtR z-score $(\beta=0.271,95 \% \mathrm{CI}=0.219$ to $0.324, \mathrm{p}<0.001)$, heart rate (beats per minute) $(\beta=0.019,95 \% \mathrm{CI}=0.015$ to $0.023, \mathrm{p}<0.001)$ and the child's perception of their body image (using Stunkard's silhouettes) ( $\beta=0.136,95 \%$ $\mathrm{CI}=0.083$ to $0.189, \mathrm{p}<0.001)$ were found to be positively associated with SBP z-score. In contrast, we found that compared with male sex, female sex had lower SBP z-score $(\beta=-0.246,95 \% \mathrm{CI}=-0.385$ to $-0.108, \mathrm{p}<0.001)$. Similarly, age (years) $(\beta=-0.060,95 \% \mathrm{CI}=-0.084$ to -0.037 , $\mathrm{p}<0.001)$, children's western acculturation score $(\beta=-0.021,95 \% \mathrm{CI}=-0.036$ to $-0.006, \mathrm{p}=0.007)$ and height $(\mathrm{cm})(\beta=-0.006,95 \% \mathrm{CI}=-0.010$ to $-0.002, \mathrm{p}=0.007)$ were negatively associated with SBP z-score. After adjustment for confounders, the association between western acculturation attenuated and became non-significant, while the association observed between height and SBP z-score became positive. Associations between children's grip strength and daily physical activity in school with SBP z-score also became significant on adjustment (table 2).

In stepwise regression analysis, the combination of age, sex, BMI z-score, heart rate and weight were observed to be the most important correlates of SBP z-score, accounting for $30 \%$ of the SBP z-score variance of South Asian children (table 3).

In unadjusted logistic regression analysis, female sex was associated with lower odds of developing systolic hypertension $(\mathrm{OR}=0.56,95 \% \mathrm{CI}=0.36$ to $0.87, \mathrm{p}=0.011)$. Associations were also observed with weight $(\mathrm{kg})$ and systolic hypertension $(\mathrm{OR}=1.02,95 \% \mathrm{CI}=1.01$ to $1.04, \mathrm{p}<0.001)$, BMI z-score and systolic hypertension $(\mathrm{OR}=2.22,95 \% \mathrm{CI}=1.84$ to 2.68, $\mathrm{p}<0.001)$, WC $\mathrm{z}$-score and systolic hypertension $(\mathrm{OR}=2.65$, $95 \% \mathrm{CI}=2.06$ to $3.43, \mathrm{p}<0.001)$ and WHtR z-score and systolic hypertension $(\mathrm{OR}=2.47,95 \% \mathrm{CI}=1.95$ to 3.13 , $\mathrm{p}<0.001)$. Similarly, associations were observed between heart rate (beats per minute) and systolic hypertension $(\mathrm{OR}=1.04,95 \% \mathrm{CI}=1.02$ to $1.06, \mathrm{p}<0.001)$, child's perception of body image and systolic hypertension $(\mathrm{OR}=1.50$, $95 \% \mathrm{CI}=1.25$ to $1.79, \mathrm{p}<0.001)$ and western acculturation score with systolic hypertension $(\mathrm{OR}=0.95,95 \% \mathrm{CI}=0.90$ to $1.00, \mathrm{p}=0.03)$. On adjustment for confounders, the associations between western acculturation score and systolic hypertension attenuated and became non-significant. The association between grip strength and systolic hypertension became significant on adjustment (figure 1).

\section{Correlates of DBP and diastolic hypertension}

In unadjusted linear regression analysis of multifactorial variables with DBP z-score, negative associations with DBP z-score were observed between age (years) $(\beta=-0.061$, $\mathrm{p}<0.001)$, height $(\mathrm{cm})(\beta=-0.009, \mathrm{p}<0.001)$, western acculturation score $(\beta=-0.018, p=0.007)$, fathers' level of education $(\beta=-0.054, p=0.047)$, total daily food intake $(\beta=-0.016$, $\mathrm{p}=0.005)$, fast foods $(\beta=-0.065, \mathrm{p}=0.048)$ and grip strength $(\mathrm{kg})(\beta=-0.019, \mathrm{p}<0.001)$. Conversely, significant positive associations with DBP z-score were observed between heart rate $(\beta=0.018, p<0.001)$, BMI $z$-score $(\beta=0.156, p<0.001)$, WC z-score $(\beta=0.120, p<0.001)$, WHtR z-score $(\beta=0.128$, $\mathrm{p}<0.001)$ and children's perception of their body image (using Stunkard's silhouettes) $(\beta=0.053, \mathrm{p}=0.007)$. After adjustment for confounders the association between height, western acculturation score, father's level of education, total daily food intake, fast food consumption and grip strength attenuated and became non-significant (table 2).

In stepwise regression analysis, the combination of age, BMI z-score, heart rate and daily intake of fast foods were observed to be the most important aggregate correlates of DBP z-score, accounting for $23 \%$ of the DBP z-score variance of South Asian children (table 3).

In unadjusted logistic regression analysis, associations were observed between age (years) $(\mathrm{OR}=0.71$, $95 \% \mathrm{CI}=0.55$ to $0.92, \mathrm{p}=0.01)$, height $(\mathrm{cm}) \quad(\mathrm{OR}=0.97$, $95 \% \mathrm{CI}=0.94$ to $1.00, \mathrm{p}=0.04)$, BMI $\mathrm{z}$-score $(\mathrm{OR}=1.68$, $95 \% \mathrm{CI}=1.31$ to $2.17, \mathrm{p}<0.001)$, WC $\mathrm{z}$-score $(\mathrm{OR}=1.89$, $95 \% \mathrm{CI}=1.32$ to $2.70, \mathrm{p}=0.001)$, WHtR $\mathrm{z}$-score $(\mathrm{OR}=1.77$, $95 \% \mathrm{CI}=1.26$ to $2.47, \mathrm{p}=0.001$ ), heart rate (beats per minute $)(\mathrm{OR}=1.06,95 \% \mathrm{CI}=1.03$ to $1.10, \mathrm{p}<0.001)$ and grip strength $(\mathrm{kg}) \quad(\mathrm{OR}=0.92,95 \% \quad \mathrm{CI}=0.86$ to 0.99 , $\mathrm{p}=0.024)$ with diastolic hypertension. On adjustment for confounders, the association between height, grip strength and diastolic hypertension attenuated and became non-significant (figure 2).

\section{DISCUSSION}

This study provides information on a range of correlates of SBP and DBP z-scores in a population of South Asian 
Table 1 Physiological, lifestyle and sociodemographic characteristics of South Asian children stratified by sex

\begin{tabular}{|c|c|c|c|c|}
\hline & Total $(n=762)$ & Boys $(n=360)$ & Girls ( $n=402)$ & $P$ value \\
\hline Age (years) & $9.5 \pm 3.0$ & $9.3 \pm 2.8$ & $9.7 \pm 3.1$ & 0.09 \\
\hline Paternal education & & & & 0.92 \\
\hline Primary education & $247(34 \%)$ & $115(34 \%)$ & $132(35 \%)$ & \\
\hline Trade school & $21(3 \%)$ & $9(3 \%)$ & $12(3 \%)$ & \\
\hline No formal education & $5(1 \%)$ & $4(1 \%)$ & $1(0 \%)$ & \\
\hline Primary education & $223(30 \%)$ & $103(30 \%)$ & $120(31 \%)$ & \\
\hline Trade school & $6(1 \%)$ & $4(1 \%)$ & $2(1 \%)$ & \\
\hline College/university & $503(68 \%)$ & $235(68 \%)$ & $268(69 \%)$ & \\
\hline Daily physical activity outside school (MET min/day) & $15.9 \pm 33.9$ & $18.5 \pm 31.3$ & $13.5 \pm 35.9$ & 0.04 \\
\hline Daily intake-servings of fruit and vegetables (daily mean intake) & $3.16 \pm 1.86$ & $3.11 \pm 1.81$ & $3.21 \pm 1.91$ & 0.485 \\
\hline Daily intake - servings of fast foods (daily mean intake) & $0.91 \pm 0.78$ & $0.86 \pm 0.59$ & $0.97 \pm 0.91$ & 0.067 \\
\hline Total daily intake-servings & $12.0 \pm 4.48$ & $12.2 \pm 4.9$ & $11.8 \pm 4.1$ & 0.243 \\
\hline Exposure to bullying/violence at school & & & & 0.025 \\
\hline Yes & $233(34 \%)$ & $126(38 \%)$ & $107(30 \%)$ & \\
\hline No & $459(66 \%)$ & $207(62 \%)$ & $252(70 \%)$ & \\
\hline Exposure to secondhand smoking* & & & & 0.616 \\
\hline None & $712(94 \%)$ & $336(94 \%)$ & $376(94 \%)$ & \\
\hline No & $280(96 \%)$ & $128(93 \%)$ & $152(98 \%)$ & \\
\hline Father's history of hypertension & & & & 0.979 \\
\hline Yes & $30(10 \%)$ & $14(10 \%)$ & $16(10 \%)$ & \\
\hline No & $260(90 \%)$ & $122(90 \%)$ & $138(90 \%)$ & \\
\hline Height (cm) & $138.3 \pm 16.5$ & $139.1 \pm 17.6$ & $137.7 \pm 15.5$ & 0.22 \\
\hline Weight (kg) & $36.5 \pm 15.8$ & $36.9 \pm 16.5$ & $36.1 \pm 15.3$ & 0.46 \\
\hline BMI z-score & $0.48 \pm 1.44$ & $0.57 \pm 1.61$ & $0.40 \pm 1.28$ & 0.11 \\
\hline WC z-score & $-0.06 \pm 1.23$ & $0.11 \pm 0.36$ & $-0.21 \pm 1.24$ & $<0.001$ \\
\hline WHtR z-score & $-0.38 \pm 1.24$ & $-0.27 \pm 1.27$ & $-0.48 \pm 1.21$ & 0.02 \\
\hline Heart rate & $87 \pm 12$ & $86 \pm 12$ & $87 \pm 13$ & 0.047 \\
\hline SBP z-score & $0.57 \pm 0.97$ & $0.70 \pm 0.99$ & $0.46 \pm 0.95$ & 0.001 \\
\hline DBP z-score & $0.37 \pm 0.71$ & $0.35 \pm 0.68$ & $0.39 \pm 0.73$ & 0.41 \\
\hline SBP (non-transformed) & $109 \pm 11$ & $111 \pm 12$ & $107 \pm 10$ & $<0.001$ \\
\hline DBP (non-transformed) & $65 \pm 8$ & $65 \pm 8$ & $65 \pm 8$ & 0.849 \\
\hline Systolic hypertension & $90(12 \%)$ & $54(15 \%)$ & $36(9 \%)$ & 0.01 \\
\hline Diastolic hypertension & $31(4 \%)$ & $13(4 \%)$ & $18(5 \%)$ & 0.55 \\
\hline
\end{tabular}

*Exposure defined as a minimum of five consecutive minutes during which inhalation of other people's smoke occurs.

BMI, body mass index; DBP, diastolic blood pressure; MET, metabolic-equivalent-of-task; SBP, systolic blood pressure; WC

waist circumference; $\mathrm{WHtR}$, waist-to-height ratio. 
Open access

Table 2 Adjusted linear regression between multifactorial risk factors with SBP and DBP z-scores

\begin{tabular}{|c|c|c|}
\hline & SBP z-score & DBP z-score \\
\hline Age (years)* & $-0.054(-0.078$ to -0.029$), p<0.001$ & $-0.057(-0.075$ to -0.039$), p<0.001$ \\
\hline Female sex (vs male) $\dagger$ & $-0.208(-0.350$ to -0.067$), p=0.004$ & $0.078(-0.023$ to 0.179$), p=0.132$ \\
\hline Weight (kg) & 0.047 (0.040 to 0.055$), p<0.001$ & 0.022 (0.016 to 0.027$), p<0.001$ \\
\hline BMI z-score & 0.292 (0.249 to 0.336$), p<0.001$ & 0.160 (0.127 to 0.193$), p<0.001$ \\
\hline Heart rate & 0.016 (0.010 to 0.022$), p<0.001$ & 0.015 (0.011 to 0.019$), p<0.001$ \\
\hline Acculturation (western score) & $-0.010(-0.026$ to 0.006$), p=0.211$ & $-0.005(-0.016$ to 0.006$), p=0.373$ \\
\hline Acculturation (traditional score) & $0.010(-0.006$ to 0.026$), p=0.227$ & $0.003(-0.008$ to 0.015$), p=0.582$ \\
\hline Child's perception of body image & 0.183 ( 0.128 to 0.239$), p<0.001$ & 0.104 (0.064 to 0.144$), p<0.001$ \\
\hline Father's history of hypertension & $-0.127(-0.484$ to 0.230$), p=0.484$ & $-0.063(-0.336$ to 0.209$), p=0.648$ \\
\hline Mother's history of hypertension & $-0.003(-0.524$ to 0.518$), p=0.991$ & $0.354(-0.042$ to 0.750$), p=0.079$ \\
\hline Grip strength (non-dominant hand) & 0.025 (0.007 to 0.043$), p=0.007$ & $0.006(-0.007$ to 0.019$), p=0.381$ \\
\hline Daily physical activity in school (MET min/day) & 0.005 (0.002 to 0.008$), p=0.003$ & 0.003 (0.001 to 0.005$), p=0.009$ \\
\hline $\begin{array}{l}\text { Daily physical activity outside school (MET min/ } \\
\text { day) }\end{array}$ & $0.001(-0.001$ to 0.003$), p=0.363$ & $0.000(-0.002$ to 0.002$), p=0.994$ \\
\hline $\begin{array}{l}\text { Daily intake-fruit and vegetables (daily mean } \\
\text { intake) }\end{array}$ & $-0.008(-0.049$ to 0.033$), p=0.717$ & $-0.011(-0.040$ to 0.018$), p=0.466$ \\
\hline Daily intake - fast foods (daily mean intake) & $0.004(-0.086$ to 0.093$), p=0.937$ & $-0.053(-0.117$ to 0.011$), p=0.104$ \\
\hline
\end{tabular}

Model adjusted for age, sex and father's education.

Values presented are $\beta$ (95\% Cls) and $p$ values.

${ }^{*}$ Age was adjusted for sex and father's education.

†Sex was for adjusted for age and father's education

BMI, bodymass index; BP, blood pressure; DBP, diastolic blood pressure; MET, metabolic-equivalent-of-task; SBP, systolic blood pressure;

WC, waist circumference; WHtR, waist-to-height ratio.

Table 3 Stepwise linear regression analysis showing the aggregate correlates of BP z-score in South Asian children

\begin{tabular}{|c|c|c|c|c|c|}
\hline \multicolumn{6}{|c|}{ Stepwise multiple linear regression models } \\
\hline & Variable & $\beta$ & $95 \% \mathrm{Cl}$ & $P$ value & Adjusted $\mathbf{R}^{2}$ \\
\hline \multirow[t]{5}{*}{ Systolic BP z-score } & Child's age & -0.132 & -0.202 to -0.062 & $<0.001$ & 0.294 \\
\hline & Sex & -0.293 & -0.461 to -0.126 & 0.001 & \\
\hline & BMI z-score & 0.125 & 0.022 to 0.228 & 0.017 & \\
\hline & Heart rate & 0.014 & 0.007 to 0.021 & $<0.001$ & \\
\hline & Weight (kg) & 0.027 & 0.012 to 0.041 & $<0.001$ & \\
\hline \multirow[t]{4}{*}{ Diastolic BP z-score } & Child's age & -0.027 & -0.048 to -0.007 & 0.01 & 0.228 \\
\hline & BMI z-score & 0.125 & 0.081 to 0.170 & $<0.001$ & \\
\hline & Heart rate & 0.015 & 0.010 to 0.021 & $<0.001$ & \\
\hline & Daily fast food intake & -0.013 & -0.028 to 0.001 & 0.072 & \\
\hline
\end{tabular}

BMI, body mass index; BP, blood pressure.

children. While results from unadjusted models highlight the presence of a multifactorial relationship for BP and hypertension, the disappearance of most of the social and lifestyle risk factors on adjustment highlights the contribution of variables, such as age, sex, adiposity, height, heart rate and grip strength, to the risk of elevated BP and hypertension in South Asian children.

It is well documented that the burden of hypertension has precipitously increased in the paediatric population. ${ }^{25}$ In addition, some studies have documented a higher 


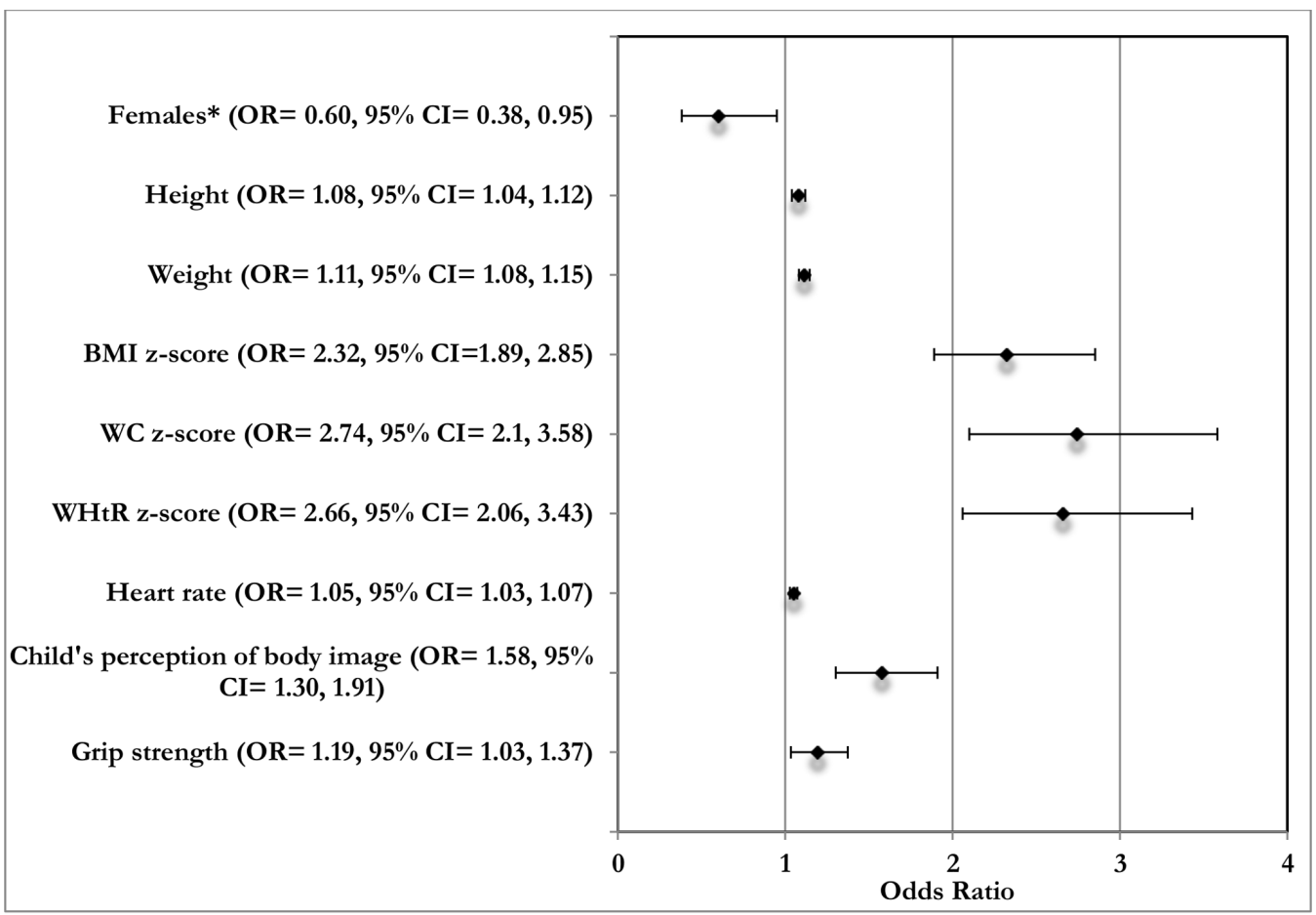

Figure 1 Adjusted OR for the association between the multifactorial variables with systolic hypertension. Model adjusted for age, sex and father's education. Values presented are OR (95\% Cls). ${ }^{*}$ Compared to males. BMI, body mass index; WC, waist circumference; WHtR, waist-to-height ratio.

prevalence of hypertension in certain ethnic groups, such as South Asians. ${ }^{11}$ Although our sample was based on convenience and non-representative given that sampling was restricted to two Canadian cities, the prevalence of hypertension in our study at $12 \%$ is consistent with age-adjusted, sex-adjusted and height-adjusted estimates from
Jafar et $a{ }^{11}{ }^{11}$ using a nationally representative survey of Pakistani children aged 5-14 years, but higher than $5.2 \%$ prevalence from one cross-sectional study of Indian children aged 5-12years ${ }^{26}$. Our estimates also appear higher than estimates from Canadian children aged 6-19 years where $7 \%$ of children were said to have hypertension

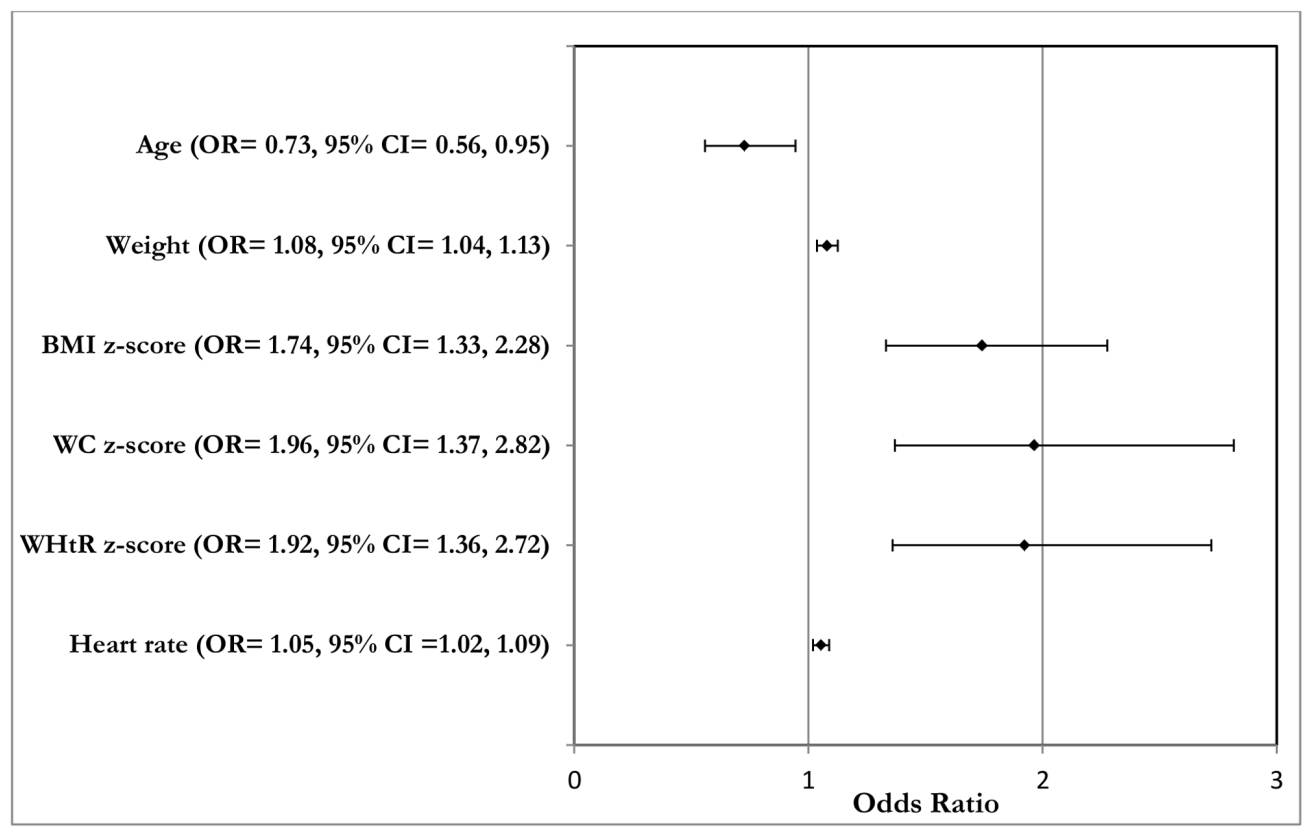

Figure 2 Adjusted OR for the association between the multifactorial variables with diastolic hypertension. Model adjusted for age, sex and father's education. Values presented are OR (95\% Cls). BMI, body mass index; WC, waist circumference; WHtR, waist-to-height ratio. 
and prehypertension. ${ }^{27}$ When stratified by sex, we found significantly higher rates were observed for boys at $15 \%$ compared with girls at $9 \%$. This is consistent with results from studies in other children, which have reported higher hypertension prevalence in boys, ${ }^{28} 29$ and results from regression analysis, which found female sex to be associated with lower odds of hypertension. This risk differential has been attributed to the presence of an anti-inflammatory immune profile in females and proinflammatory profile in males ${ }^{30}$ - underscoring the potential for intervention efforts aimed at addressing sex-based disparities.

Consistent with research conducted in South Asian children ${ }^{1131}$ and research conducted in other childhood populations of different ethnicities, ${ }^{28}{ }^{32-36}$ we observed positive associations between measures of adiposity and $\mathrm{BP}$ and hypertension after adjusting for covariates. The consistency of the association observed across the range of adiposity metrics assessed underscores the significant contribution of increasing adiposity to the prevalence of hypertension in South Asian children. Moreover, the positive association between grip strength (a measure of muscle strength) with SBP z-score and hypertension on adjustment in this study raises questions about the benefits of strength training in children. The benefits of physical activity including aerobic exercise in relation to hypertension remain clear; however, the benefits of strength training in relation to hypertension risk, relative to the benefits of aerobic exercise, appear questionable. ${ }^{37}$ It is unclear what might be responsible for the positive effect observed between grip strength and SBP z-score; however, findings from our study appear consistent with studies that have explored this association in Chinese ${ }^{38}$ and American children. ${ }^{39}$

The consistent association between adiposity and hypertension, including the higher prevalence of hypertension in this population, reinforces their connections through a range of complex mechanistic pathways. Some of these pathways involve the activation of the reninangiotensin-aldosterone system or sympathetic nervous system. Specifically, the South Asian phenotype of higher body fat $^{7}$ - especially the visceral type, which has been identified in adults ${ }^{6}$ - when compared with their Caucasian peers, could activate the formation of proinflammatory cytokines, such as interleukin 6 , which results in physiological changes that could lead to endothelial and vascular dysfunction through the development of insulin resistance, ${ }^{40}$ resulting in an increased predisposition for hypertension. The positive association between height and BP in this population could be explained by cerebral perfusion requirements where higher $\mathrm{BP}$ is needed in taller people to achieve optimal cerebral perfusion owing to hydrostatic pressure differences in taller and shorter individuals. ${ }^{41}$ However, more research in South Asian children is warranted to corroborate our findings given the difference observed in direction of association in unadjusted and adjusted models.

The positive association we found between the child's perception of body image and BP may be due to this variable mirroring children's weight status or conversely, a marker for a graded increase in stress levels, owing to societal criticism of fatter body types, which could have insidious effects for hypertension risk through its impact on the neuroendocrine system. ${ }^{42}$ Additionally, a range of social and lifestyle variables was also found to be associated with BP z-score in unadjusted analysis but became non-significant on adjustment for confounders. While results from unadjusted associations may demonstrate links between risk factor and outcome, the disappearance of the association on adjustment for sociodemographic variables highlights the links between these variables and suggests that the pathway linking these factors with BP might be interdependent.

The stepwise regression model shows that correlates from this study explained only about $30 \%$ of the variance of SBP z-score and $23 \%$ of the variability of DBP z-scores. It is possible that some of this unexplained variance might be explained by genetics, as it has been suggested that about $30 \%-60 \%$ of the variance in BP may be heritable. ${ }^{434}$ Yet the lack of association between parental hypertension and child BP in the subset of parents of participants who provided this data would appear to contradict these findings for this population of South Asian children. However, it is likely that the subset of parents of child participants who provided this information might not be completely representative of the entire cohort, thereby biasing the results. Still, even accounting for potential genetic contributions, a significant amount of the $\mathrm{BP}$ variance remains unexplained. More research is needed to provide insight regarding the contributory effects of other potential variables that might contribute to the risk of elevated BP in South Asian children.

Notably, null associations were also observed for certain variables, in this study, which have been found to be significantly associated with BP and hypertension in other child populations. For example, parental history of hypertension, dietary factors (such as consumption of fruit and vegetables) and exposure to secondhand smoking have been linked in other studies to child BP but had no significant impact in this study. This could be reflective of the potential biases associated with using self-reports or may highlight how interactions between genes and environment/lifestyle shape risk factor susceptibilitiesunderscoring the need for more ethnic-based and ethnic comparison studies when exploring risk associations.

\section{Study limitations}

This study has limitations. First, although we sought to recruit a representative sample of urban South Asian children, it was not a random sample. However, there is likely to be minimal effect on the relationships between the ranges of risk factors evaluated in this study. Second, this is a cross-sectional study and is, therefore, unable to provide insights into causal associations between the risk factor variables and long-term CVD risk in South Asian children. Third, potential recall biases may have occurred as a result of using self-report data for some of the 
variables including diet and physical activity measures. Fourth, the use of father's education as a measure of socioeconomic status pose limitations. Variables, such as household income, would have been preferred; however, only a subset of participants provided data on household income; thus, its use would have excluded a significant portion of children in this study. However, as a means to confirm the results, we separately adjusted for mother's education and no deviation in study results was observed. Last, the lack of data collection on sexual maturity status could potentially confound the study results obtained here. However, the adjustment for age in this study, which acts as a proxy variable for sexual maturity might help to mitigate the bias. These limitations are in part addressed by strengths of this study, which lies in its large sample size of South Asian children and in the wide range of risk factors examined.

\section{Implications}

Our findings underscore a range of factors that may contribute to the risk of elevated BP and hypertension in South Asian children. Consequently, public health interventions such as those that emphasise prevention, such as population-based health education and lifestyle modification, and that considers unique cultural contexts may provide significant potential in addressing the burden of hypertension in this population. There are also implications for clinical settings. Specifically, our findings suggest that while South Asian children may benefit from interventions aimed at reducing obesity to address the comparatively higher burden of hypertension in this population, there are certain subgroups who could benefit from more targeted preventive interventions in primary care settings-such as males, children with increased adiposity, taller children and children with increased heart rate, or children with a combination of these factors.

\section{CONCLUSION}

In this group of South Asian children, we found associations between a range of physiological, social and lifestyle factors with BP z-scores and hypertension. However, on adjustment for confounders, physiological variables, such as age, sex, height, adiposity and heart rate, remained consistently associated with BP and hypertension, and provided the strongest explanatory effect for the variance in BP. Given the sequelae associated with elevated BP, including BP tracking from childhood into adulthood, these results provide evidence on modifiable risk factors that might be targeted by prevention strategies in primary care to reduce the burden of high BP and hypertension in South Asian children.

Acknowledgements SL is the Pfizer/Heart and Stroke Foundation Chair in Cardiovascular Prevention Research at St. Paul's Hospital. Research coordinators Pam Mackie, Michelle Tsigoulis, Veronica de Jong, Vaven Ghaat, Erica Corber and Amanpreet Thind were instrumental in completing the data collection for this project.
Contributors SL, ZP, KMM, MG, KT and SR conceptualised the study, contributed to the study design and reviewed the manuscript. AF conceptualised the study, drafted the initial manuscript, carried out the statistical analysis and revised the manuscript. CW and MR contributed to the design of the study, and reviewed and revised the manuscript. All authors approved the final manuscript as submitted.

Funding This study was funded by the Canadian Institutes of Health Research (FRN: 109206).

Disclaimer All authors agree to be accountable for all aspects of the work.

Competing interests None declared.

Patient consent for publication Not required.

Ethics approval The study is approved by the Simon Fraser University Research Ethics Board (REB), the Providence Health Care REB and the Hamilton Integrated REB.

Provenance and peer review Not commissioned; externally peer reviewed.

Data sharing statement Raw data are held by the lead author of the study in accordance with the ethics guidelines.

Open access This is an open access article distributed in accordance with the Creative Commons Attribution Non Commercial (CC BY-NC 4.0) license, which permits others to distribute, remix, adapt, build upon this work non-commercially, and license their derivative works on different terms, provided the original work is properly cited, appropriate credit is given, any changes made indicated, and the use is non-commercial. See: http://creativecommons.org/licenses/by-nc/4.0/.

\section{REFERENCES}

1. Bureau PR. World Population Data Sheet. PRB's 2017 World Population Data Sheet. 2017.

2. Canada S. Immigration and Ethnocultural Diversity in Canada. National Household Survey, 2011. National Household Survey, 2011. 99-010-X2011001.

3. UK Office for National Statistics. Ethnicity and National Identity in England and Wales. Http://Www.Ons.Gov.Uk.

4. Hoeffel EM, Rastogi S, Kim MO. The Asian Population: 2010. 2010 Census Briefs 2012:1-23.

5. Anand SS, Yusuf S, Vuksan V, et al. Differences in risk factors, atherosclerosis, and cardiovascular disease between ethnic groups in Canada: the Study of Health Assessment and Risk in Ethnic groups (SHARE). Lancet 2000;356:279-84.

6. Lear SA, Humphries KH, Kohli S, et al. Visceral adipose tissue accumulation differs according to ethnic background: results of the Multicultural Community Health Assessment Trial (M-CHAT). Am J Clin Nutr 2007;86:353-9.

7. Eyre E, Duncan M, Nevill A. South Asian Children Have Increased Body Fat in Comparison to White Children at the Same Body Mass Index. Children;4:102.

8. WHO. A Global Brief on Hypertension, 2013.

9. Chen X, Wang Y. Tracking of blood pressure from childhood to adulthood: a systematic review and meta-regression analysis. Circulation 2008;117:3171-80.

10. Soudarssanane M, Mathanraj S, Sumanth M, et al. Tracking of blood pressure among adolescents and young adults in an urban slum of puducherry. Indian J Community Med 2008;33:107-12.

11. Jafar TH, Islam M, Poulter N, et al. Children in South Asia have higher body mass-adjusted blood pressure levels than white children in the United States: a comparative study. Circulation 2005;111:1291-7.

12. Henderson $\mathrm{EJ}$, Jones $\mathrm{CH}$, Hornby-Turner YC, et al. Adiposity and blood pressure in 7- to 11-year-old children: comparison of British Pakistani and white British children, and of British Pakistani children of migrant and British-born mothers. Am J Hum Biol 2011;23:710-6.

13. Fowokan AO, Sakakibara BM, Onsel N, et al. Correlates of elevated blood pressure in healthy children: a systematic review. Clin Obes 2018;8:366-81.

14. Stunkard AJ, Sørensen T, Schulsinger F. Use of the Danish Adoption Register for the study of obesity and thinness. Res Publ Assoc Res Nerv Ment Dis 1983;60:115-20.

15. Ws L, Sy H, Mak KK, et al. The Use of Stunkard's Figure Rating Scale to Identify Underweight and Overweight in Chinese Adolescents. PLoS One 2012.11.

16. Birch LL, Fisher JO, Grimm-Thomas K, et al. Confirmatory factor analysis of the Child Feeding Questionnaire: a measure of parental attitudes, beliefs and practices about child feeding and obesity proneness. Appetite 2001;36:201-10. 
17. Rivara F, Le MS, et al. Prevention $\mathrm{C}$ on the $\mathrm{B}$ and $\mathrm{PE}$ of $\mathrm{PVL}$ for $\mathrm{B}$. Preventing Bullying Through Science, Policy, and Practice: National Academies Press (US), 2016. 10.17226/23482.

18. Stigler M, Dhavan P, Van Dusen D, et al. Westernization and tobacco use among young people in Delhi, India. Soc Sci Med 2010;71:891-7.

19. Iqbal $\mathrm{R}$, Anand $\mathrm{S}$, Ounpuu $\mathrm{S}$, et al. Dietary patterns and the risk of acute myocardial infarction in 52 countries: results of the INTERHEART study. Circulation 2008;118:1929-37.

20. Roberts HC, Denison HJ, Martin HJ, et al. A review of the measurement of grip strength in clinical and epidemiological studies: towards a standardised approach. Age Ageing 2011;40:423-9.

21. de Onis M, Onyango AW, Borghi E, et al. Development of a WHO growth reference for school-aged children and adolescents. Bull World Health Organ 2007;85:660-7.

22. Sharma AK, Metzger DL, Daymont C, et al. LMS tables for waistcircumference and waist-height ratio Z-scores in children aged 5-19 y in NHANES III: association with cardio-metabolic risks. Pediatr Res 2015;78:723-9.

23. National High Blood Pressure Education Program Working Group on High Blood Pressure in Children and Adolescents. The fourth report on the diagnosis, evaluation, and treatment of high blood pressure in children and adolescents. Pediatrics 2004:114:555-76.

24. von Elm E, Altman DG, Egger M, et al. The Strengthening the Reporting of Observational Studies in Epidemiology (STROBE) statement: guidelines for reporting observational studies. J Clin Epidemiol 2008;61:344-9.

25. Din-Dzietham R, Liu Y, Bielo MV, et al. High blood pressure trends in children and adolescents in national surveys, 1963 to 2002. Circulation 2007;116:1488-96.

26. Genovesi S, Antolini L, Gallieni M, et al. High prevalence of hypertension in normal and underweight Indian children. $J$ Hypertens 2011;29:217-21.

27. Statistics Canada. Blood pressure of Canadian children and youth, 2012 to 2015.2016 https://www150.statcan.gc.ca/n1/pub/82-625-x/ 2016001/article/14659-eng.htm (Accessed 20 March 2019).

28. Huntington-Moskos L, Turner-Henson A, Rice M. Tobacco exposure, weight status, and elevated blood pressure in adolescents. $J$ Community Health 2014;39:653-9.

29. Leung LC, Sung RY, So HK, et al. Prevalence and risk factors for hypertension in Hong Kong Chinese adolescents: waist circumference predicts hypertension, exercise decreases risk. Arch Dis Child 2011;96:804-9.
30. Gillis EE, Sullivan JC. Sex Differences in Hypertension: Recent Advances. Hypertension 2016;68:1322-7.

31. Goel M, Pal P, Agrawal A, et al. Relationship of body mass index and other life style factors with hypertension in adolescents. Ann Pediatr Cardiol 2016;9:29.

32. Moser DC, Giuliano IdeCB, Titski ACK, et al. Anthropometric measures and blood pressure in school children. $J$ Pediatr 2013;89:243-9.

33. Flores-Huerta $\mathrm{S}$, Klünder-Klünder $\mathrm{M}$, Reyes de la Cruz $\mathrm{L}$, et al. Increase in body mass index and waist circumference is associated with high blood pressure in children and adolescents in Mexico city. Arch Med Res 2009;40:208-15.

34. Wang H, Necheles J, Carnethon M, et al. Adiposity measures and blood pressure in Chinese children and adolescents. Arch Dis Child 2008;93:738-44.

35. Mirzaei M, Taylor R, Morrell S, et al. Predictors of blood pressure in a cohort of school-aged children. Eur J Cardiovasc Prev Rehabil 2007;14:624-9.

36. Lurbe E, Torro I, Rodríguez C, et al. Birth weight influences blood pressure values and variability in children and adolescents. Hypertension 2001;38:389-93.

37. Pescatello LS, MacDonald HV, Lamberti L, et al. Exercise for Hypertension: A Prescription Update Integrating Existing Recommendations with Emerging Research. Curr Hypertens Rep $2015 ; 17: 87$

38. Dong B, Wang Z, Arnold L, et al. The association between blood pressure and grip strength in adolescents: does body mass index matter?. Hypertens Res 2016;39:919-25.

39. Zhang R, Li C, Liu T, et al. Handgrip Strength and Blood Pressure in Children and Adolescents: Evidence from. 2011;31:792-6.

40. Vaněčková I, Maletínská L, Behuliak M, et al. Obesity-related hypertension: possible pathophysiological mechanisms. J Endocrinol 2014;223:R63-R78.

41. Roth JV. Taller People Should Have as Their Normal a Higher Body Mass Index. Anesthesiology 2018;128:424.

42. Spruill TM. Chronic Psychosocial Stress and Hypertension. Curr Hypertens Rep 2010;12:10-16.

43. Vehaskari VM. Heritable forms of hypertension. Pediatr Nephrol 2009;24:1929-37.

44. Ehret GB. Genome-wide association studies: contribution of genomics to understanding blood pressure and essential hypertension. Curr Hypertens Rep 2010;12:17-25. 